\title{
Partial characterisation of a soluble haemagglutinin from human diarrhoeal isolates of Aeromonas
}

\author{
G. A. STEWART, CHRISTINE S. BUNDELL* and VALERIE BURKE*
}

\section{Clinical Immunology Research Unit and *Gastroenterology and Nutrition Research Unit, Princess Margaret} Children's Medical Research Foundation, Perth, Australia

\begin{abstract}
Summary. A soluble haemagglutinin has been identified in cell-free culture supernates of human diarrhoeal isolates of Aeromonas sobria, A. hydrophila and A. caviae. It was oligomeric; a major peak of haemagglutinating activity had an apparent mol. wt of 780000 but there was haemagglutinating activity throughout the mol. wt range $<40000->10^{6}$. Human group $\mathrm{O}, \mathrm{A}$ and $\mathrm{B}$, horse, rabbit, chicken and rat erythrocytes, but not those of sheep and cow, were agglutinated by the soluble haemagglutinin, in contrast to the cell-bound agglutinin. Agglutination was inhibited by fetuin, a complex glycoprotein, but not by simple sugars. The haemagglutinating activity was not affected by $0.5 \mathrm{M} \mathrm{NaCl}$, dithiothreitol or the presence or absence of $\mathrm{Ca}^{++}$. It was unrelated to the haemolytic, enterotoxigenic and proteolytic activities present in cellfree extracts of $A$. sobria. All $A$. sobria, $73 \%$ of $A$. hydrophila and $68 \%$ of $A$. caviae strains tested produced this soluble haemagglutinin. $A$. caviae does not appear to be an enteric pathogen, therefore this soluble haemagglutinin alone is unlikely to be a virulence factor in Aeromonas spp.
\end{abstract}

\section{Introduction}

Adherence of intestinal pathogens to the gut mucosa precedes diarrhoea, whether this is caused by enterotoxins or by invasion of intestinal epithelium. Haemagglutination has been widely used for characterisation of such adhesins. Cell-associated fimbrial haemagglutinins are important in the virulence of Escherichia coli (Satterwhite et al., 1978). Several patterns of cell-associated haemagglutination have been detected with strains of Aeromonas spp. grown on solid media (Atkinson and Trust, 1980; Burke et al., 1984a) but adhesins of Aeromonas spp. may be fimbrial (Atkinson and Trust, 1980) or non-fimbrial (Chang et al., 1985). Their role as possible virulence factors is not known, but fucoseresistant haemagglutination correlates well with clinical isolates (Burke et al., 1984b).

Soluble haemagglutinins produced by strains grown in liquid media have been reported in Vibrio cholerae (Finkelstein and Hanne, 1983) and may be important virulence factors (Finkelstein et al., 1983). Soluble haemagglutinins of $V$. parahaemolyticus have also been described (Oishi et al., 1979) but their significance is unknown. We have studied the production of soluble haemagglutinins by Aeromonas.

Received 26th Jun. 1985; accepted 31st Jul. 1985.

\section{Materials and methods}

\section{Bacteria}

Aeromonas spp. were identified according to the methods of Popoff (1984). Three strains were chosen for study: $A$. sobria isolated from an adult in Perth; $A$. hydrophila from a Thai adult; and $A$. caviae from an Indonesian child. All three patients had diarrhoea. We had previously shown that the strains of $A$. sobria and $A$. hydrophila were cytotoxic, haemolytic and enterotoxigenic (Burke et al., $1981 a$ ) but the $A$. caviae strain did not produce cytotoxin, haemolysin or enterotoxin.

Growth conditions. Bacteria were stored at room temperature in maintenance medium. For the preparation of large batches of broth culture, bacteria were grown either on a blood-agar plate overnight at $37^{\circ} \mathrm{C}$ or in a $5-\mathrm{ml}$ volume of Trypticase Soy Broth (Oxoid) with Yeast Extract L21 (Oxoid) $0.6 \% \mathrm{w} / \mathrm{v}$ (TSB-YE) in 50-ml Erlenmeyer flasks until growth was clearly visible (5-6 h at $37^{\circ} \mathrm{C}$ ). These cultures were used to inoculate about 16 $50-\mathrm{ml}$ volumes of TSB-YE in 250-ml Erlenmeyer flasks, which were incubated for $24 \mathrm{~h}$ at $37^{\circ} \mathrm{C}$ and $300 \mathrm{rpm}$ on an environmental shaker (New Brunswick Scientific, New Jersey, USA); each batch comprised c. $800 \mathrm{ml}$ of broth culture. All cultures were checked for purity by subculture on to blood-agar plates which were incubated overnight at $37^{\circ} \mathrm{C}$.

Cell-free supernates of culture were prepared by centrifuging the broth cultures at $5000 \mathrm{rpm}$ for $30 \mathrm{~min}$ at $4^{\circ} \mathrm{C}$ (Sorvall, GSA rotor), and then filtering the supernate 
under vacuum through a $0.45-\mu \mathrm{m}$ membrane filter (type HA, Millipore Corp., Bedford, USA). This cell-free preparation was extensively dialysed against $0.05 \mathrm{M}$ $\mathrm{NH}_{4} \mathrm{HCO}_{3}$ at $4^{\circ} \mathrm{C}$, and was then lyophilised and resuspended in a minimal volume of distilled water.

\section{Toxin preparation}

Crude toxins were precipitated from the cell-free preparation with cold saturated $\left(\mathrm{NH}_{4}\right)_{2} \mathrm{SO}_{4} 80 \% \mathrm{v} / \mathrm{v}$. The precipitate was collected by centrifugation at $10000 \mathrm{rpm}$ (Sorvall, SM-24 rotor) for $15 \mathrm{~min}$ at $4^{\circ} \mathrm{C}$ and washed twice in a minimal amount of $80 \%$ saturated $\left(\mathrm{NH}_{4}\right)_{2} \mathrm{SO}_{4}$, dialysed extensively against $0.5 \mathrm{M} \mathrm{NH}_{4} \mathrm{HCO}_{3}$ at $4{ }^{\circ} \mathrm{C}$ and lyophilised. This crude toxin preparation was stored at $-20^{\circ} \mathrm{C}$ until required for further purification. Alternatively, the culture supernates were concentrated in dialysis tubing with Aquacide (Calbiochem Behring, Australia), dialysed against $0.05 \mathrm{M} \mathrm{NH}_{4} \mathrm{HCO}_{3}$ and lyophilised.

Gel filtration. The crude toxin preparation was filtered at $4^{\circ} \mathrm{C}$ on a Sephacryl S-300 (Pharmacia, South Seas Pty. Ltd) column $(162 \times 2.6 \mathrm{~cm})$, poured according to the manufacturer's instructions and equilibrated with $0 \cdot 1 \mathrm{M}$ tris- $\mathrm{HCl}$ buffer, $p \mathrm{H} 8$, containing $0 \cdot 15 \mathrm{M} \mathrm{NaCl}$. The lyophilised material was resuspended in column buffer and filtered through a membrane prefilter (Millipore), then applied to the top of the column and fractionation achieved at a flow rate of $30 \mathrm{ml} / \mathrm{h}$. Fractions $(c .5 \mathrm{ml})$ were collected on an LKB Ultrorac fraction collector and the optical density at $280 \mathrm{~nm}$ determined by a flow-through spectrophotometer (Pharmacia, South Seas Pty. Ltd). Relevant fractions were pooled, extensively dialysed against $0.5 \mathrm{M} \mathrm{NH}_{4} \mathrm{HCO}_{3}$, concentrated with Aquacide and stored at $-20^{\circ} \mathrm{C}$ until required. Gel filtration on Fractogel HW 55F (Merck, W. Germany) was performed in $0 \cdot 1 \mathrm{M}$ tris- $\mathrm{HCl}$ buffer containing $0.3 \mathrm{M} \mathrm{NaCl}$.

\section{Assays}

Enterotoxin assay. The suckling-mouse system was used to assay enterotoxigenic activity as described previously (Burke et al., 1981b). Every second fraction from the gel-filtration run was assayed. Controls included the column buffer (negative control) and a fresh cell-free preparation of the $A$. sobria strain (positive control).

Haemolysin and haemagglutinin assays. The haemolytic and haemagglutinating activities of the gel-filtered fractions were assayed in microtitration trays with either human group $\mathrm{O}$ or rabbit erythrocytes $(\mathrm{rbc}) 1 \% \mathrm{v} / \mathrm{v}$. To $100-\mu$ l volumes of serial twofold dilutions of individual

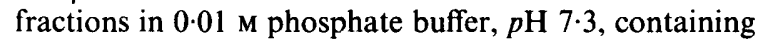
$0.15 \mathrm{M} \mathrm{NaCl}$ (PBS) was added an equal volume of $\mathrm{rbc}$. The trays were incubated at $37^{\circ} \mathrm{C}$ and the haemolytic or haemagglutinating titres were the highest dilutions that showed either haemolysis or agglutination after incubation for $1 \mathrm{~h}$ at $37^{\circ} \mathrm{C}$.

Species specificity of haemagglutinin. Rbc obtained from cattle, sheep, horses, chickens and rats as well as rabbit and human $\mathrm{O}, \mathrm{A}$, and $\mathrm{B}$ cells were used to assay the haemagglutinating activity of the fractions from the Sephacryl S-300 gel-filtration runs.

Effect of temperature on haemolytic and haemagglutinating activity. Pooled fractions from the Sephacryl S-300 fractionation of the cell-free supernate from $A$. sobria with either haemagglutinating or haemolytic activity were incubated at $56^{\circ} \mathrm{C}$ in a water bath and $100-\mu$ l samples removed at $0,0 \cdot 5,5,10,15,30,60$ and $120 \mathrm{~min}$ for assay with rabbit rbc.

Inhibition of haemagglutinating activity. Pooled fractions from the Sephacryl S-300 fractionation of supernate from $A$. sobria with high haemagglutinating activity were diluted to give a haemagglutination titre of 10 , and $50-\mu 1$ volumes of this dilution were preincubated with an equal volume of serial twofold dilutions of the sugars, amino acids and proteins listed in table II for $1 \mathrm{~h}$ at $37^{\circ} \mathrm{C}$. Rabbit rbc $1 \% \mathrm{v} / \mathrm{v}(100 \mu \mathrm{l})$ were then added and the haemagglutination recorded after incubation for $1 \mathrm{~h}$ at $37^{\circ} \mathrm{C}$.

Effect of chemical reduction on the haemagglutinin. Pooled haemagglutinating fractions were incubated with $0 \cdot 1 \mathrm{M}$ dithiothreitol for $1 \mathrm{~h}$ at $37^{\circ} \mathrm{C}$ and haemagglutinating activity determined with rabbit rbc.

Protease activity. The proteolytic activity of the fractions from the Sephacryl S-300 gel filtration of the $A$. sobria supernates was determined with the general proteolytic enzyme substrate Azocoll (Calbiochem-Behring Pty. Ltd, Australia). The amount of red product released was measured with a spectrophotometer by absorption at $520 \mathrm{~nm}$. Protease activity was also determined by the casein-agar-lysis method (Sokol et al., 1979).

\section{Physico-chemical studies}

The mol. wts of the haemagglutinin and haemolysin from $A$. sobria were determined either by gel-filtration chromatography on Sephacryl S-300 or Fractogel HW 55 $\mathrm{F}$ or by gradient polyacrylamide gel electrophoresis $(2.5$ $27 \%$; Gradient Laboratories, Australia; G-PAGE). The mol.-wt markers used in gel filtration included thyroglobulin (mol. wt 669000), albumin (67000), ovalbumin (43000), $\alpha$-chymotrypsinogen (25 700) and ribonuclease (13700). Markers used for G-PAGE included thyroglobulin, ferritin $(440000)$ catalase $(232000)$ lactase dehydrogenase (140000) and albumin (67000). After electrophoresis, the G-PAGE gels were cut into $0.5-\mathrm{cm}$ wide sections and the gel disrupted in a teflon-coated pestle. The material contained therein was eluted with PBS and the eluate tested for haemagglutination and haemolysis.

\section{Survey of soluble haemagglutinin among Aeromonas} spp.

Assay for soluble haemagglutinin was performed with 70 strains of $A$. sobria, 55 of $A$. hydrophila and 75 of $A$. caviae. Cell-free preparations from haemolytic strains were heated to $56^{\circ} \mathrm{C}$ for $1 \mathrm{~min}$; these conditions had been shown to abolish haemolytic activity and thus allow detection of haemagglutination. 


\section{Results}

\section{Fractionation of cell-free supernates}

Fractions of the cell-free supernate from $A$. sobria separated on Sephacryl S-300 were assayed for total protein and haemolytic, haemagglutinating, proteolytic and enterotoxic activities.

Haemagglutination occurred in the high-mol.-wt region of the elution profile with the peak of activity eluting at a position corresponding to a protein with an apparent mol. wt of 780000 . In contrast, the major haemolysin peak eluted at a position corresponding to a mol. wt of 34000 ; a smaller peak of haemolytic activity co-eluted with the high-mol.-wt haemagglutinin. Haemagglutinin and haemolysin each eluted as broadly based peaks, suggesting hetereogeneity with regard to apparent mol. wt. A similar profile was also obtained by gel filtration on a Fractogel column; similar apparent mol. wts were obtained for the haemagglutinin but the apparent mol. wt of the haemolysin was 55000 .

Preparative G-PAGE studies in which electrophoresed material was eluted and tested for haemagglutinating activity also showed that the haemagglutinin was heterogeneous. Haemagglutinating activity was present throughout the gel (mol.-wt range $<40000$ to $>10^{6}$ ). Haemolytic activity was also detected in this and subsequent assays by a blood-agarose overlay technique. Two bands of haemolysis were observed corresponding to proteins with mol. wts of 127000 and 110000 .

Enterotoxic activity measured by the suckling mouse assay corresponded in elution position and profile with haemolytic activity. Similarly, a small peak of enterotoxic activity co-eluted with the haemagglutinin and the high-mol.-wt haemolysin. Protease eluted at a position corresponding to a protein with an apparent mol. wt of 14000 . Protease activity was not detected in association with the haemagglutinating activity by use of either Azocoll or casein-agar substrates.

G-PAGE studies showed that haemagglutinin was also produced by $A$. hydrophila and by $A$. caviae. Gel filtration showed two haemagglutinin peaks in $A$. caviae supernates, the high-mol.-wt fraction eluting in the same position as the haemagglutinin of $A$. sobria and the low-mol.-wt fraction eluting in the same position as the haemoly$\sin$ of $A$. sobria. There was no haemolytic activity in the $A$. caviae supernate. The haemagglutinins of $A$. hydrophila and $A$. caviae like that of $A$. sobria were heterogeneous with regard to apparent mol. wt as judged by preparative G-PAGE.

\section{Characteristics of the haemagglutinin}

Properties of the soluble haemagglutinin were compared with those of cell-bound haemagglutinins of Aeromonas spp. The soluble haemagglutinin agglutinated rbc from various species (table I), including horse, rabbit, chicken, rat and human $(\mathrm{O}$, $\mathrm{A}$ and $\mathrm{B})$. The highest haemagglutinin titres were found with rabbit and chicken rbc, but sheep or cow rbc were not agglutinated. In contrast, cell-bound haemagglutinin agglutinated all species of rbc tested, including those of sheep and cow. The soluble haemagglutinin was unaffected by the presence or absence of $\mathrm{Ca}^{++}$or by the chelating agent EDTA.

The inhibition profile of the haemagglutinin was determined with various compounds including sugars, amino acids and glycoproteins (table II). Of the sugars, only lactose inhibited haemagglutination but this activity was variable; haemagglutination-inhibition titres were in the range 0-32. Empirical observations suggested that the inhibitory capacity of lactose varied with the source of rabbit cells. None of the amino acids inhibited haemagglutination, and of the other compounds tested, only fetuin was inhibitory.

The thermal labilities of haemagglutinin and haemolysin were determined (table III). Both were labile at $56^{\circ} \mathrm{C}$. However, the haemolysin was much more sensitive to heat than the haemagglutinin; at $56^{\circ} \mathrm{C}$, haemolytic activity was abolished within 30 $\mathrm{sec}$ whereas haemagglutination was abolished only after $10 \mathrm{~min}$. Haemagglutinating activity was detected in the haemolysin fraction after heating.

Table I. Reactivity of the soluble and cell-bound haemagglutinins from $A$. sobria with erythrocytes from various species

\begin{tabular}{lcc} 
Erythrocytes & $\begin{array}{c}\text { Soluble } \\
\text { haemagglutinin } \\
\text { titre* }\end{array}$ & $\begin{array}{c}\text { Cell-bound } \\
\text { agglutinin } \\
\text { titre** }\end{array}$ \\
\hline Human O & 16 & 64 \\
Human A & 16 & 64 \\
Human B & 16 & 64 \\
Horse & 8 & 16 \\
Rabbit & 64 & 128 \\
Chicken & 32 & 64 \\
Rat & 16 & 64 \\
Sheep & 0 & 64 \\
Cow & 0 & 64 \\
\hline
\end{tabular}

* The haemagglutinin used was the high-mol.-wt fraction from Sephacryl S-300 gel filtration.

** Agglutination of $A$. sobria cells by erythrocytes. 
Table II. Inhibition of haemagglutination of rabbit rbc by the haemagglutinin from $A$. sobria

\begin{tabular}{lcc}
\hline Inhibitor & $\begin{array}{c}\text { Initial } \\
\text { concentration } \\
\text { of inhibitor } \\
(\mathrm{mg} / \mathrm{ml})\end{array}$ & $\begin{array}{c}\text { Haemag- } \\
\text { glutination- } \\
\text { inhibition } \\
\text { titre* }\end{array}$ \\
\hline L-Arabinose & 50 & 0 \\
Dulcitol & 50 & 0 \\
D-Fructose & 50 & 0 \\
N-Acetyl D-galactosamine & 50 & 0 \\
N-Acetyl D-glucosamine & 50 & 0 \\
L-Rhamnose & 50 & 0 \\
L-Sorbose & 50 & 0 \\
L-Fucose & 50 & 0 \\
D-galactose & 50 & 0 \\
D-glucose & 50 & 0 \\
D-mannose & 50 & 0 \\
$\alpha$-Methyl-mannoside & 50 & 0 \\
Lactose & 50 & $8 \dagger$ \\
Sialic acid & 50 & 0 \\
Ovalbumin & 1 & 0 \\
Bovine serum albumin & 1 & 0 \\
Fetuin & 1 & 32 \\
Creatine & 13 & 0 \\
Alanine & 9 & 0 \\
Arginine & 17 & 0 \\
Lysine & 18 & 0 \\
\hline & & \\
\hline
\end{tabular}

* Haemagglutination-inhibition titres are expressed as the reciprocal of the highest dilution of inhibitor solution that inhibited haemagglutination; the haemagglutinin was the high-mol.-wt fraction from Sephacryl S-300 gel filtration.

† The inhibitory activity of lactose in this system was highly variable; titres were in the range $0-32$.

Table III. The influence of heat $\left(56^{\circ} \mathrm{C}\right)$ upon the stability of haemagglutinin and haemolysin from $A$. sobria

\begin{tabular}{|c|c|c|c|c|}
\hline \multirow{2}{*}{$\begin{array}{l}\text { Time of exposure } \\
\text { to } 56^{\circ} \mathrm{C} \text { (min) }\end{array}$} & \multicolumn{2}{|c|}{$\begin{array}{l}\text { Titres in the } \\
\text { HAG* fraction }^{*}\end{array}$} & \multicolumn{2}{|c|}{$\begin{array}{l}\text { Titres in the } \\
\text { HL* fraction }^{*}\end{array}$} \\
\hline & HAG & HL & HL & $\mathrm{HAG}$ \\
\hline 0 & 32 & 0 & 16 & ND \\
\hline 0.5 & 16 & 0 & 0 & 4 \\
\hline 5 & $8-16$ & 0 & 0 & 4 \\
\hline 10 & 2 & 0 & 0 & 4 \\
\hline 15 & 0 & 0 & 0 & 4 \\
\hline 30 & 0 & 0 & 0 & 2 \\
\hline 60 & 0 & 0 & 0 & 0 \\
\hline
\end{tabular}

* The haemagglutinin (HAG) and haemolysin (HL) used were the major fractions from Sephacryl S-300 gel filtration. $\mathrm{ND}=$ not detected because of haemolysis.

This too was abolished by heat but only after incubation for $30 \mathrm{~min}$. Neither haemolysin nor haemagglutinin were affected by reduction with dithiothreitol.
Previous studies of the fimbrial and heat-labile agglutinins of Bordetella pertussis (Askelöf et al., $1982)$ indicated that a high salt concentration $(0.5 \mathrm{M}$ $\mathrm{NaCl}$ ) inhibited haemagglutination by fimbrial but not by heat labile haemagglutinin. Thus, haemagglutination experiments with gel-filtration fractions from the strain of $A$. sobria were performed in the presence of $0.15 \mathrm{M} \mathrm{NaCl}$ or $0.5 \mathrm{M} \mathrm{NaCl}$; no difference was found.

Soluble haemagglutinin in other strains of Aeromonas spp.

All strains of $A$. sobria, 40 of 55 strains of $A$. hydrophila and 51 of 75 strains of $A$. caviae tested produced soluble haemagglutinins.

\section{Discussion}

Although soluble haemagglutinins of $V$. cholerae (Finkelstein and Hanne, 1983) and $V$. parahaemolyticus (Oishi et al., 1979) are recognised, production of haemagglutinins detectable in cell-free preparations from broth cultures by Aeromonas spp. has not been reported previously. The soluble haemagglutinins from strains of $A$. sobria, $A$. hydrophila and $A$. caviae demonstrated in this study had properties different from the cell-associated haemagglutinin of Aeromonas spp. previously described (Atkinson and Trust, 1980; Burke et al., 1984a). Cell-bound haemagglutinin reacted with all species of rbc tested, but soluble haemagglutinin did not agglutinate rbc from sheep or cows. Furthermore, the soluble haemagglutinin could not be inhibited by simple sugars such as L-fucose, Dgalactose or D-mannose, although lactose produced inconsistent inhibition. The glycoprotein fetuin was the only compound tested that consistently inhibited haemagglutination by the soluble haemagglutinin.

These properties are similar to those of the soluble haemagglutinins of $V$. cholerae (Finkelstein and Hanne, 1983) which are heat labile and unaffected by reduction with dithiothreitol and are not inhibited by simple sugars, a characteristic shared by some soluble haemagglutinins of $V$. parahaemolyticus (Oishi et al., 1979).

The soluble haemagglutinins from Aeromonas spp. and $V$. cholerae exists in an oligomeric form. The mol. wt of the $V$. cholerae sub-unit is 32000 , similar to that of the low-mol.-wt haemagglutinin peak in cell-free supernates of $A$. caviae cultures. However, the relationship between the high-mol.wt and the low-mol.-wt haemagglutinins in Aeromonas spp. is unknown. 
Physico-chemical studies by gel-filtration and GPAGE showed that the soluble haemagglutinin of Aeromonas spp. was a heterogeneous high-mol.-wt component comprising a major peak with an apparent mol. wt of 780000 . G-PAGE studies showed that the soluble haemagglutinins had apparent mol. $w t s$ in the range $<40000->10^{6}$. The haemagglutination profile did not parallel proteolytic, haemolytic or enterotoxigenic activities of Aeromonas spp. The $V$. cholerae haemagglutinin hydrolyzes several different protein substrates (Finkelstein et al., 1983). We have been unable to demonstrate any correlation between haemagglutination and proteolytic activity in Aeromonas spp.

Gel-filtration studies showed that the apparent mol. wt of the haemolysin was 34000 but the elution profile suggested that the haemolysin was heterogeneous with regard to mol. wt; previous studies have shown that the apparent mol. wt of isolated haemolysin in the presence of sodium dodecyl sulphate or urea is 50000 (Bernheimer and Avigad, 1974; Buckley et al., 1981). The G-PAGE studies described here indicated that the haemolysin comprised two components with apparent mol. wts of 110000 and 127000 . Previous studies have suggested that the haemolysin is heterogeneous with regard to charge (Asao et al., 1984). These data suggest that in normal aqueous systems the haemolysin aggregates or interacts in some way with the separating matrix. This conclusion is supported by

\section{REFERENCES}

Asao T, Kinoshita Y, Kozaki S, Uemura T, Sakaguchi G 1984 Purification and some properties of Aeromonas hydrophila hemolysin. Infection and Immunity 46:122-127.

Askelöf P, Granström M, Gillenius P, Lindberg A A 1982 Purification and characterisation of a fimbrial haemagglutinin from Bordetella pertussis for use in an enzyme-linked immunosorbent assay. Journal of Medical Microbiology 15:73-83.

Atkinson H M, Trust T J 1980 Hemagglutination properties and adherence ability of Aeromonas hydrophila. Infection and Immunity 27:938-946.

Bernheimer A W, Avigad L S 1974 Partial characterization of aerolysin, a lytic exotoxin from Aeromonas hydrophila. Infection and Immunity 9:1016-1021.

Buckley J T, Halasa L N, Lund K D, Macintyre S 1981 Purification and some properties of the hemolytic toxin aerolysin. Canadian Journal of Biochemistry 59:430-435.

Burke V, Cooper M, Robinson J, Gracey M, Lesmana M, Echeverria P, Janda J M $1984 a$ Hemagglutination patterns of Aeromonas spp. in relation to biotype and source. Journal of Clinical Microbiology 19:39-43.

Burke V, Robinson J, Atkinson H M, Dibley M, Berry R J, Gracey M 1981a Exotoxins of Aeromonas hydrophila. Australian Journal of Experimental Biology and Medical Science 59:753-761. gel-filtration studies in the presence of $1 \mathrm{M}$ urea (Asao et al., 1984) and by the gel-filtration studies on Fractogel described here in the presence of high salt concentrations. Gel filtration on Fractogel indicated that the haemolysin had an apparent mol. wt 55000. The haemolysin profile was shown to parallel that of the enterotoxigenic activity, which suggests that the haemolysin had enterotoxigenic activity, as had been observed previously (Hośtacká et al., 1982).

Although haemolytic and enterotoxic activities in $A$. sobria correlate with isolation of the strain from faeces rather than the environment and with the presence of diarrhoea (Burke et al., 1984b), no such association has been found with the soluble haemagglutinin described here in $A$. sobria, $A$. hydrophila and $A$. caviae. This latter organism appears not to be an enteric pathogen (Burke et al., 1984b). Therefore, the soluble haemagglutinin alone would not seem to be a virulence factor but it may facilitate colonisation and contribute to the virulence of those Aeromonas spp. capable of producing diarrhoea by enterotoxin production (Burke et al., 1984) or by invasion of epithelial cells (Watson et al., 1985).

This work was supported financially by the Princess Margaret Children's Medical Research Foundation. We thank Jan Beaman, Christine Groessler, Karen Lees and Ann Nisbet for technical assistance.

Burke V, Robinson J, Berry R J, Gracey M $1981 b$ Detection of enterotoxins of Aeromonas hydrophila by suckling-mouse test. Journal of Medical Microbiology 14:401-408.

Burke V, Robinson J, Cooper M, Beaman J, Partridge K, Peterson D, Gracey M $1984 b$ Biotyping and virulence factors in clinical and environmental isolates of Aeromonas species. Applied and Environmental Microbiology 47:11461149.

Chang B J, Lawson M A, Silburn K A 1985 Adhesive and invasive properties of Aeromonas hydrophila. Australian Microbiologist 6:193.

Finkelstein R A, Hanne L F 1983 Hemagglutinins (colonization factors?) produced by Vibrio cholerae. In: Kuwahara $\mathrm{S}$, Pierce N F (eds) Advances in research on cholera and related diarrheas. Proceedings of the 17 th Joint Conference on Cholera. Nijhoff, Boston, pp 121-125.

Finkelstein R A, Boesman-Finkelstein M, Holt P 1983 Vibrio cholerae hemagglutinin/lectin/protease hydrolyzes fibronectin and ovomucin: F M Burnet revisited. Proceedings of the National Academy of Sciences of the USA 80:1092-1095.

Hośtacká A, Ciženár I, Korych B, Karolček J 1982 Toxic factors of Aeromonas hydrophila and Plesiomonas shigelloides. Zentralblat für Bakteriologie, Mikrobiologie und Hygiene 1. Abt. Orig. A 252:525-534.

Oishi K, Yokoshima S, Tomiyama T, Aida K 1979 Exohemagglutinins; New Products of Vibrios. Applied and Environmental Microbiology 38:169-172. 
Popoff M 1984 Aeromonas Kluyver and Van Niel 1936, 398 ${ }^{\mathrm{AL}}$. In: Krieg N R, Holt J G (eds) Bergey's manual of systematic bacteriology, vol 1. Williams and Wilkins, Baltimore, pp 545-548.

Satterwhite T K, Evans D G, Dupont H L, Evans D J 1978 Role of Escherichia coli colonisation factor antigen in acute diarrhoea. Lancet 2:181-184.
Sokol P A, Ohman D E, Iglewski B H 1979 A more sensitive plate assay for detection of protease production by Pseudomonas aeruginosa. Journal of Clinical Microbiology 9:538-540.

Watson I M, Robinson J O, Burke V, Gracey M 1985 Invasiveness of Aeromonas spp. in relation to biotype, virulence factors and clinical features. Journal of Clinical Microbiology 22:48-51. 